\title{
SUSTAINABLE DRUGS AND GLOBAL HEALTH CARE
}

\author{
Geoffrey A. Cordell \\ Natural Products Inc., Evanston, IL 60203, U.S.A.
}

Recebido em 29/5/2008; publicado na web em 17/6/09

\begin{abstract}
Each day, Earth's finite resources are being depleted for energy, for material goods, for transportation, for housing, and for drugs. As we evolve scientifically and technologically, and as the population of the world rapidly approaches 7 billion and beyond, among the many issues with which we are faced is the continued availability of drugs for future global health care. Medicinal agents are primarily derived from two sources, synthetic and natural, or in some cases, as semi-synthetic compounds, a mixture of the two. For the developed world, efforts have been initiated to make drug production "greener", with milder reagents, shorter reaction times, and more efficient processing, thereby using less energy, and reactions which are more atom efficient, and generate fewer by-products. However, most of the world's population uses plants, in either crude or extract form, for their primary health care. There is relatively little discussion as yet, about the long term effects of the current, non-sustainable harvesting methods for medicinal plants from the wild, which are depleting these critical resources without concurrent initiatives to commercialize their cultivation. To meet future public health care needs, a paradigm shift is required in order to adopt new approaches using contemporary technology which will result in drugs being regarded as a sustainable commodity, irrespective of their source. In this presentation, several approaches to enhancing and sustaining the availability of drugs, both synthetic and natural, will be discussed, including the use of vegetables as chemical reagents, and the deployment of integrated strategies involving information systems, biotechnology, nanotechnology, and detection techniques for the development of medicinal plants with enhanced levels of bioactive agents.
\end{abstract}

Keywords: synthetic drugs; medicinal plants; green chemistry.

\section{INTRODUCTION}

After decades of discussion and debate, most of the leaders of the world now recognize that human development is having a measurable, detrimental effect on the climate of the Earth, and hence the environment and living conditions for billions of people. In this respect, three events in 2007 marked this dramatic global shift: The publication of the Fourth Assessment Report of the Intergovernmental Panel on Climate Change (IPCC), the awarding of the 2007 Nobel Peace Prize to the IPCC and Al Gore for his writing and the film "An Inconvenient Truth", and the UN climate change conference in Bali. These events, and numerous political, scientific, and economic meetings all over the world have brought into sharper focus the need for action, while continuing debate and discussion. Predictions for the world's current climate are described as "dire" in the IPCC report. ${ }^{1}$ The same conclusion was reached in 2006 in the first report of the Chinese government on climate change. ${ }^{2}$ This focus on the steady increase of temperatures in many parts of the Earth follows a twenty-year period where there was increasing concern expressed about other aspects of the impact of human civilization on Earth's resources because of deforestation and eco-destruction. This rising tide of international environmental concern culminated in April, 2005, with the United Nations Millennium Ecosystem Assessment which indicated for the first time that "...the ability of ecosystems to sustain future generations can no longer be taken for granted...". 3

Earth's oil, coal, and mineral resources are finite, and somewhat unknown in both quantity and location as accessible economic commodities. Such data are closely guarded secrets for obvious political and strategic reasons. Thus, estimates of the potential duration of these resources, given the vagaries of the parameters of population growth, expanding economic development, and the growth of alternative energy

Conferência convidada apresentada na $31^{\mathrm{a}} \mathrm{RASBQ}$

*e-mail: pharmacog@gmail.com sources, etc. vary from tens to hundreds of years. On the other hand, terrestrial plants, for food, for a variety of other human needs, or for medicinal plants, even when cultivated in the simplest manner, are a potentially renewable resource. However, in most parts of the world, the pressures on both the original resources, and the land needed to produce them on a renewable basis are enormous, for one simple reason, population growth. Thus, while we may continue to discuss the significance of human development on climate change and renewable resources, these are outcomes of the cause, not the cause itself. Until we address the cause, our discussions are only a salve for a growing tumor on Gaia, our inextricably interwoven biosphere we call Earth. But the discussions must continue, if only to emphasize the terrible outcomes that humanity will face, whether they be flooding in low-lying coastal areas, or desertification inland. ${ }^{4}$ In either circumstance, it is likely that billions of people will be negatively impacted.

Concerns with respect to future energy resources, and for continuing access to quality water and food have received widespread discussion in both the scientific and popular arenas, and are starting to develop political interest at the policy level. On the other hand, much less attention has been given to the burgeoning global need for synthetic and natural medicinal agents; as a topic of concern it barely makes it to the level of discussion of scientific societies.

Most of the previous discussions from this author on the development of traditional medicines have focused on the many aspects of quality control, including safety, efficacy, shelf-life, and plant drug-synthetic drug interactions. ${ }^{5-10}$ As a result, a vision for the comprehensive future quality control and development of medicinal plants was proposed. ${ }^{5,8-12}$ Here, some background and discussion on a closely related topic will be presented, namely, the need for drugs, both synthetic and natural, to be made available on a sustainable basis, thereby extending that public health vision for quality medicinal agents. In addition, some aspects of what declining access to resources might mean for primary health care for the world in the future are presented, together with some alternative strategies. 
This will not be an exhaustive review of the issues surrounding the sustainable development of synthetic drugs and medicinal plants globally, but it is intended to highlight some of the considerations involved and some selected, on-going efforts in various parts of the world, and indicate where new initiatives are needed for the future. It will then begin to expand on the notion of how plants can be collected in the field in a more ethically reasonable and less destructive manner; the concept of "pharmacognosy in a suitcase".

\section{THE “GREAT DIVIDE”}

Access to quality health care is an enormous public health global issue at the scientific, clinical, economic, political and policy levels. It is one aspect of the "great divide" that exists between and within every country in the world; it is the difference in access to health care between the rich and the poor. ${ }^{13}$ For example, health care investment per capita in the United States is approximately \$6,096, in Brazil it is $\$ 1,520$, and in Ethiopia it is $\$ 21$ per capita. ${ }^{14}$ Yet, even within the US, it is estimated that 47 million people, about $15 \%$ of the population, has no health insurance. ${ }^{15}$ In terms of the delivery of medicinal agents, there are tremendous disparities between the numbers of doctors and the number of traditional healers in many countries of the world (vide infra). As a direct result, there is a very different mix of health care practices and a corresponding diversity of natural and synthetic drugs being used in different countries by various populations. Populations in the urban areas are more likely to follow allopathic medical practices, while those in rural areas, who have no access to allopathic medicine, rely on local healers and local medicinal plants. The quality of the health care that is associated with the different origins of medicinal agents is likewise extremely different, and is reflected in the regulations applied to traditional medicines and synthetic drugs. In May, 2005, WHO published a summary of regulations applied to traditional medicines around the world based on a survey of all 191 member countries. ${ }^{16}$ Only $74 \%$ of the countries responded (the U.S. did not respond) and only 53 had some form of regulations in place. There was no assessment made of the nature of the regulations with respect either to safety or efficacy of the traditional medicines, or of the sustainability of the medicinal plants being used. For many people in the world, even in urban areas, this quality of health care has barely changed in 4,000 years of human development. For others, there is the assumption that the majority ( $80 \%$ or more) of their high drug costs will be borne by health insurance.

Based on a lack of scientific training and/or on necessity, there are vastly differing views of the validity (safety and efficacy) of the various resources for medications within a given country. For some of the more affluent people in the world, there are options for the sourcing of their medicinal agents. For those who are economically challenged, those options may be extremely limited. Almost twentyfive years ago, a WHO-associated group, based on an earlier paper, ${ }^{17}$ provided a guesstimate that $80 \%$ of the population in the developed world relies on plants for their primary health care. ${ }^{18}$ Although this is a widely quoted figure, it has yet to be scientifically validated. As the resources to provide medicinal agents become scarcer, and because of the long term public health necessity of relying on plant-based traditional medicines, this number merits rigorous scientific determination on a global basis in order that more accurate assessments of resource need versus availability can be made for future health care.

At the same time, as economies evolve in various parts of the world, and as populations migrate to the urban areas, traditional medicinal plant use may be modulated in favor of synthetic drugs. Consequently, for both synthetic and natural medicinal agents there is the need to have more refined estimates of the level of non-renewable resources that are needed for making those agents available, and the tonnages of chemicals, solvents, reagents, catalysts, and medicinal plants that are required annually in order to support local health care systems. From such studies, the net amount of non-renewable resources used each year can be projected, and in the case of medicinal plants, the acreage required for cultivation. As we shall see, the contemporary practices of wild-crafting of the medicinal plants of commerce cannot be a long-term option for health care, recognizing also that socially and economically it is a complicated issue. ${ }^{19}$

A more practical example of the significant financial and accessibility challenges facing global health care is represented by aspirin and Elaprase. Introduced in 1899 by the Bayer Company, aspirin is the most widely consumed drug in the world (ca. 35,000 metric tons per year). ${ }^{20}$ It is the quintessential drug, with a long ethnomedical history, which is now a totally synthetic commodity at a daily prescription cost of 3.5 cents. ${ }^{21}$ Yet, even at this price, it cannot be made available to a global population in desperate need of even the simplest pain medication. At the other end of the economic scale there is Elaprase at $\$ 300,000$, the most expensive drug in the world on an annual basis, available only to the elite few with exceptional health insurance. ${ }^{22}$

In terms of drug discovery and development for the diseases that predominate in the less-developed world there is also a "great divide". ${ }^{23}$ Of the 1556 new medicines approved between 1975 and 2004, only $1.3 \%$ (20) were for diseases prevalent in the less-developed world, including tuberculosis. ${ }^{24}$ Almost no major pharmaceutical company has a commitment to drug discovery for tropical diseases. The implications are therefore simple and clear. In any given less-developed country, primarily, it will be the responsibility of the local academic and pharmaceutical institutions to develop the medicinal agents for local diseases. ${ }^{5,9-12}$ In addition, most countries of the world will have to weigh the public health and economic questions of whether it will be more effective to develop local resources for the production of selected synthetic medicinal agents, or to rely on imported drugs, and establish, based on indigenous and imported resources, where validated traditional medicines fit into a health care program.

From the perspective of medicinal agents, health care in the future will be a blended mixture of allopathic medicine based on synthetic and natural drugs, and traditional medicine based on plants and fungi. At one end of the spectrum will be those people in a particular country who use, by choice and economic option, only the allopathic system. At the other end of the health care spectrum will be those people who, based on necessity, can only use the traditional medicine system. In between will be those people taking a greater or lesser extent of traditional and allopathic medicines in some form of integrated system of health care.

\section{THE RESOURCES NEEDED}

As mentioned above, concomitant with the depletion of the Earth's resources of oil, gas, and coal, there will be an increasing need to establish accurate estimates of the non-renewable resources required each year to produce synthetic and natural drugs and traditional medicines and their derived products. The total, non-renewable chemical resources required on an annual basis by the major pharmaceutical industries of the world to produce synthetic and semi-synthetic drugs have not been calculated. All attempts to access such information have thus far proved fruitless. As accountability for the depletion of non-renewable resources increases, pharmaceutical industry will be under increasing international pressure to make these data available, and to modulate their practices for drug production.

Concern for the use and continuing availability of plants as medicinal agents has been documented for over 4,000 years, and dates to the Sumerians, who were probably the first to cultivate medicinal plants such as opium and bring them to commerce. Medicinal plant 
uses by various human groups throughout the world have been variably documented and the data assembled and published. There are, for example, the compilations in the Chinese, Indian, and Middle Eastern traditions, and more recently, the many herbals and volumes on materia medica used in Europe for hundreds of years. As a result, there are numerous documented medicinal uses of plants, albeit the information is widely scattered. In addition, there are medicinal uses which remain as undocumented ethnomedical preparations prescribed by healers in indigenous groups all over the world. Together, these medicinal plant preparations are the bedrock foundation of global primary health care.

Some medicinal plant materials are gathered as needed and simply used locally, being an essential commodity providing a meager family income through selling at a local market, whereas other medicinal plants are important entities in global trade. It is estimated that over 400,000 tonnes of medicinal and aromatic plants are in global commerce each year, involving possibly as many as 53,000 plant species, ${ }^{19}$ although that number of plants seems to be high. However, it is also estimated ${ }^{19}$ that more than $90 \%$ of those materials are harvested in a non-sustainable manner, and that perhaps more than 4,000 of these plants are threatened. Consequently, as global population increases and as health demands increase, the pressure on those plants in their native habitat is intensified when indiscriminate collection, rather than cultivation, occurs, and when the marketing of a particular plant accelerates global commercial demand. Regulation of the trade in medicinal plants may curtail their use, permanently or temporarily, or it may lead to the illegal acquisition of desirable plants

It was concern for these conservation and trade issues regarding many non-human species which led to the Convention on International Trade in Endangered Species (CITES), which was adopted at a meeting of the International Union for the Conservation of Nature in 1963, and came into force in 1975. One hundred and seventy-two parties have signed the Convention, ${ }^{25}$ although $50 \%$ of the parties do not meet the four requirements to be a Party to the Convention. Plants under different degrees of threat are listed in the separate Appendices; approximately 298 species of plants are listed in Appendix 1 (threatened with extinction if trade is not halted), 28,000 species in Appendix 2 (not-threatened with extinction, but require export/import permission), and 45 species in Appendix 3 (request to control trade between Parties). ${ }^{25}$

In many countries of the world, commercial providers of medicinal plants face a moral conflict, since several of the top selling products (e.g. goldenseal, American ginseng, and black cohosh in the U.S.) are also at the top of the "at-risk" plant list. ${ }^{26}$ Should retailers continue to sell those products? Some retailers in the US have already chosen not to do so. Should there be a requirement to indicate the sourcing of the plant and the plant CITES status on the package label (e.g. wild-crafted and threatened)? Where is the public health line between conservation through activism and market demand driving cultivation? At what point does a government need to step in to provide stricter regulatory control to prevent the loss of critical medicinal plant species and actually promote appropriate cultivation strategies as an ecological and an economic development? What are the certification standards that should be developed for both cultivated and wild-crafted plant materials?

Medicinal plant availability is also controlled to an extent when a country implements trade regulations which either ban, or set quotas for, their exportation. Wild Panax ginseng is regarded as extinct in Korea, where the government held a monopoly on sales until 1996, and where commercial cultivation, harvesting, and shipping remain carefully controlled. However, the illicit commerce (smuggling) of medicinal plants of high value, such as wild-crafted Asian ginseng (Panax ginseng) is a serious problem in far-eastern Russia and north-eastern China where at least $600 \mathrm{~kg} /$ year are gathered in a non-sustainable manner. In the US, plant materials such as American ginseng (Panax quinquefolius) are under pressure from poaching in the national parks. ${ }^{27}$ In South Africa, urbanization has brought the practice of visiting a sangoma to the cities. As a result, the need to have medicinal plants available in the cities has led to numerous arrests of plant poachers on Table Mountain in Cape Town. ${ }^{28}$ The positive outcome, however, was the establishment of a local committee which is working between ecologists and the sangomas to establish nurseries for critical medicinal plant species.

\section{ENDANGERED AND THREATENED MEDICINAL PLANT SPECIES}

The need to protect medicinal plants from exploitation has probably existed since their value was first demonstrated through low throughput clinical screening. It is certainly not a new phenomenon. ${ }^{29}$ In the past twenty years though, there has been increasing concern with respect to assessing the future availability of medicinal plants locally, and some of these efforts will be briefly discussed.

India has been the country most concerned about the conservation of its medicinal plants. As a result, there is a developing literature on the efforts to initiate conservation projects for the preservation of important Ayurvedic, Unani and other medicines. ${ }^{30,31}$ It is estimated that India has 45,000 plant species, of which as many as 15,000 may be used medicinally. However, it has also been estimated that more than $90 \%$ of the raw material for medicinal plants in India are derived from wild harvesting, ${ }^{32-34}$ and that between 4,000 to 10,000 medicinal plant species in India face extinction locally, nationally, or regionally. ${ }^{35}$ Of 71 medicinal plant species classified as "rare", $92 \%$ are in active trade, and $74 \%$ are traded nationally, ${ }^{36}$ and the quantity of Ayurvedic plants exported in the period 2001-2003 tripled. ${ }^{37}$ The Department of the Indian Systems of Medicine and Homeopathy in the Ministry of Health and Welfare ${ }^{38}$ and the Ministry of Environment and Forests, with the Government of India Planning Commission ${ }^{39}$ have initiatives conserving and cultivating important medicinal plants.

Other initiatives for the conservation of medicinal plants occur at the level of the provincial government. Thus, the Government of Andhra Pradesh, with about 1,800 species of medicinal plants in the State, has taken steps to conserve the gene pool and to promote ex situ cultivation..$^{40}$ Among these steps are stopping illicit plant trading, enhancing public awareness, developing economic cultivation practices, developing local medicines for national and international trading, reforesting degraded areas with medicinal plant species, and creating a databank of existing medicinal plants in the wild. ${ }^{40}$ The Government of Sikkim has established the Lampokhri Medicinal Plants Conservation Zone ${ }^{41}$ for the development of ex situ gene banks of medicinal plants in the alpine zone of the Greater Himalayas. Several other conservation areas for medicinal plants in India have also been described. ${ }^{42}$

Himalayan medicinal plants and the details of their trading have been the subject of quite detailed and interesting studies. ${ }^{43}$ Kala and co-workers have provided an evaluation of the problems and some remedies for medicinal plant development in northern India, and the impact on local economies. ${ }^{37} \mathrm{An}$ assessment of 49 medicinal plants in the Himalayan region used for 34 different indications estimated potential yearly needs and determined that 24 plants were regarded as being in annual short supply. ${ }^{37}$ In other studies, ${ }^{44}$ the population density of threatened medicinal plant species in seven protected areas in the Indian Himalayas was assessed through interviewing 83 Tibetan and 55 Ayurvedic healers. Sixty medicinal plants used for 45 different ailments were found to be threatened, and 32 of these were endemic to the Himalayan region. The establishment of medicinal plant conservation areas, integrated with local area kno- 
wledge, and a more detailed study of the management of such areas, and monitoring the population trends for critically important plants was recommended. ${ }^{44}$

In Ghana, there are 110 people for every traditional healer, yet only one trained physician for every 21,000 people. In Malawi, there are 17,000 traditional practitioners and 35 medical doctors. Similar situations exist in Tanzania, Mozambique, Uganda, and Swaziland. ${ }^{45}$ Yet, through most of the colonial era, the practices of traditional medicine were regarded as primitive, and were sometimes declared illegal, thereby not promoting their development as a crop. More recently, it has become clear that primary health care involving medicinal plants has created intense pressure on resources due to indiscriminate harvesting. ${ }^{45} \mathrm{~A}$ survey based on 17 countries published in 1998 by TRAFFIC East/Southern Africa identified 102 species of medicinal plants as priorities for conservation and management. ${ }^{45}$ Several issues were suggested as being detrimental to medicinal plant development and where government support was needed including, lack of technology for post-harvesting processing, scientific documentation, and low prices for growers. ${ }^{45}$

The market for traditional medicines in southern Africa is estimated at R3.1 billion (US \$75 million) annually and represents 20,000 tons of plants. However, that market is substantially threatened by the reduction of resources due to wild-crafting. ${ }^{46}$ As a result, the livelihoods of 130,000 medicinal plant traders, 200,000 traditional healers, and the primary health care of at least 26 million patients are threatened. Some proposals have been made to strengthen the situation through the sponsorship of research, the development of a five-year strategy in the directorate of the Department of Health in South Africa, and the enactment of laws which give knowledge holders more legal rights of reward.

Conserve Africa is a group that is concerned about the sustainable use and conservation of medicinal plants, and has sponsored several meetings and workshops in various parts of Africa discussing the issues related to conservation. ${ }^{47}$ Their four-point plan may be summarized as: i) identifying medicinal plants under threat, ii) preserving the knowledge to retain medicinal plant diversity, iii) propagating medicinal plant nurseries at the local level, and iv) promoting awareness of the importance of medicinal plants, their conservation, and the bio-diversity knowledge associated with them. It appears to be a sound basis for raising consciousness and for the development of local resources. However, it does not address the myriad of issues related to quality control of traditional medicines.

China, in part because of a long and well-documented history of traditional medicine, is the world's largest trader of medicinal plants, exporting over 144,000 tons of medicinal plants annually, while importing only about 9,200 tons. ${ }^{48}$ Some estimates indicate that $96 \%$ of these species are collected from the forests. ${ }^{49}$ An example of an indigenous group in Western China offers some interesting insights into the local demands for medicinal plants.

A study of medicinal plant use by the Lisu people in Nujiang Prefecture in northwest Yunnan Province found 52 medicinal plants in 32 families being used locally. ${ }^{50}$ Of these, $80 \%$ were wild-crafted, $8 \%$ were cultivated, and $12 \%$ were semi-cultivated; 11 of the species are regarded as rare or threatened. The study is almost a microcosm of the global situation. For example, i) informants in the study indicated that fewer plants were used now due to extensive deforestation, and ii) local knowledge of plant use has not been passed on. With respect to the latter situation, a local woman who kept a birth control remedy secret passed away without releasing the knowledge to anyone. The Lisu collect and trade in medicinal plants as a source of meager income, earning about US\$122 each year. Not unexpectedly, almost all of the scarce and endangered medicinal plants have both the greatest healing and the greatest economic values. ${ }^{50}$ The parasitic fungus Cordyceps sinensis, for example, ranks at the top of both lists.
Pei and co-workers ${ }^{51}$ have discussed in a national report of China, the critical importance of designating areas for medicinal plant conservation and development with a particular focus on the rich lands and flora of the Himalayan region of southwest China and the provinces of Sichuan, Qinghai, Gensu, and Yunnan, as well as Tibet. Yunnan Province alone is estimated to have over 17,000 higher plants, of which 12,000 may be "useful". About 4,758 of these species are medicinal plants within the national list of 9,935 species of Traditional Chinese Medicines (TCM). The report indicates several causes for the concerns in China for the future development of TCM as a source of local health care: i) deforestation and habitat alteration; China loses about $1 \%$ of its total forest area to deforestation each year, ii) over-harvesting of wild medicinal plants; of the top 1,000 species of plants used in TCM, 500-600 are only wild-crafted, and 200 of these are collected in the Himalayan region, iii) degradation through over-grazing and gold-mining; cattle ranching has increased substantially, and gold-mining has caused substantial habitat loss, and finally, iv) socioeconomic factors, such as changes in supply market, population shifts to urban areas, etc.

Brazil, with an estimated almost 55,000 native species, has at least 1,200 documented medicinal plants, and probably many more undocumented species used by various indigenous groups. The National Center for Genetic Resources and Biotechnology, in collaboration with other government and academic research centers has been establishing a series of germplasm collections of species of interest. Vieira ${ }^{52}$ has reviewed these developments, describing the locations of the five forest genetic reserves and four in the process of being created, for the preservation of forest species, as well as medicinal and aromatic plants. Thirty-one species of medicinal plant are listed as being of a priority for germplasm collection and conservation. It is not clear how many species of medicinal plant are in commerce in Brazil, nor how much of that commercial plant material is wild-crafted.

\section{DISCUSSION}

A brief outline was offered in the previous section regarding some of the issues faced globally with respect to increasing global population and the increased demand and enhanced marketing of synthetic drugs and the use of non-renewable resources, and the expanding use of medicinal plants without appropriate considerations for conservation. In this section, some alternative, sustainable approaches for synthetic drugs and medicinal plants will be discussed.

\section{Drug synthesis and "green" chemistry}

As described in the Rio Declaration on Environment and Development, sustainable development requires the examination of all aspects of our planetary existence for the potential to replace a depleting resource with a sustainable resource. In terms of health care, we have not yet begun to do this for pharmaceutical agents. Although it might be argued that antibiotic production was an early attempt at this, in reality the driving force in this instance was one of production control, and therefore predictable unit cost for a finished product and anticipated profit.

About 15 years ago, the concepts and practice of "green" chemistry were initiated, in which there began a shift away from reagents, substrates that are not renewable, i.e. not fossil- or mineral-based, or which cannot be recycled with high efficiency, or which are detrimental to the environment. These changes in approach necessitate profound philosophical and process changes ${ }^{53,54}$ As these changes in philosophy evolved in the chemical process industry several years ago, a set of twelve principles were developed to encapsulate the concepts and outcomes resulting from "green" strategies. ${ }^{55}$ More succinc- 
tly ${ }^{11,12,56}$ these principles can be stated as the need for: i) recyclable and safer solvents, ii) more energy efficient reaction conditions, iii) recyclable (or at least catalytic) reagents, iv) renewable feedstocks which do not deplete the resources of the planet, v) avoiding unnecessary reaction steps (such as protection reactions) and aiming for atom economy, and vi) generating reaction by-products which are environmentally friendly and of minimal toxicity.

As a result of these efforts, there have been dramatic shifts in the use of solvents (such as developing reactions for aqueous systems), catalysts and biocatalysis, reducing energy requirements for reactions, and modulating non-renewable waste ${ }^{57}$ An issue of Chemical Reviews has focused recently on more than 20 aspects of the research that are going on to develop "green" chemistry. ${ }^{58}$

Not surprisingly, most of these efforts have occurred in the developed world. For the less-developed world, there is a quite different situation for organic chemistry, involving customs, import taxes, high cost of reagents, and delayed supplies for glassware and even simple reagents such as a mineral acid, and that's all before any experiment can be initiated and the products separated and characterized. These are cogent reasons why there are so few synthetic organic chemistry groups in the less-developed world. When chemical industry does develop natural resources the results can be disastrous. The most polluted areas in the world are in Azerbaijan, China, India, Peru, Russia, the Ukraine, and Zambia, and all are based on the processing of natural resources for heavy metals or coal. ${ }^{59}$ Some of these metals are used for a variety of synthetic organic reactions.

Another aspect of sustainability concerns the introduction of new drugs and the creation of new markets for those drugs. Of the 1,035 new drugs that were approved by the US Food and Drug Administration between 1989 and 2000, over $75 \%$ were classed as having no therapeutic advantage over drugs already on the market, ${ }^{60}$ and a Canadian study showed that these drugs were responsible for $80 \%$ of the rise in prescription costs. ${ }^{24}$ Such profligate waste of resources, with no demonstrable health benefit can no longer be tolerated as we view more critically the non-renewable synthesis of most prescription products. Future drug introductions should be required to demonstrate significantly enhanced efficacy, increased safety, and their environmental impact and sustainability should be evaluated.

Is there anything that can be done to reduce (or even remove) the dependence of organic reactions on heavy metal reagents and catalysts? Can the need for the importation of finished chemicals be met by developing local chemical industries that are based on more environmentally acceptable approaches to chemical and drug manufacture?

One alternative approach, and one that has also been used in the developed world, is biocatalysis for synthetic organic transformations. This work has relied significantly on the isolation of specific enzymes (such as esterases or oxidoreductases) to explore their reactivity and specificity. As a result, the commercialization of selected enzyme preparations is well-established. ${ }^{61}$ Some of these "reagents" have been derived from microbial sources, including fungi and yeasts, while others have been crude plant preparations. But is it possible that the enzyme purification step isn't necessary? Perhaps all one needs to accomplish do certain organic reactions is a plant (or a part thereof), some water, and the substrate.

Plants are very busy chemical factories. A plant may produce 100-1000 compounds of perhaps 20-50 different structure types, unevenly distributed in various compound classes such as terpenes, shikimic acid products, acetogenins, phenylpropanoids, and possibly some alkaloids. Such chemical skeletal and functional group diversity within a given plant organism represents a plethora of corresponding chemical transformations, from oxidations and reductions, to carboncarbon bond formations and skeletal rearrangements, to esterfications and hydrolyses, to methylations, and glycosylations. All of these reactions are conducted under exquisite enzymatic control, and frequently with exceptional levels of enantiospecificity. What is not known, since so few of these enzymes have been characterized, is their substrate specificity. One cheap and readily available local plant source with which to examine this question of substrate specificity (and therefore potential synthetic utility) is the vegetables.

\section{Vegetables as chemical reagents}

We recently provided a review of the study of various vegetables as chemical reagents. ${ }^{56}$ It is now well-established that carrots (Daucus carota), manihot (Manihot escuela and Manihot dulcis), and coconut juice (Cocos nucifera) can perform a number of significant organic chemical transformations, including the reduction of ketones and aldehydes, the reduction of double bonds, and various esterification and hydrolysis reactions. As appropriate, these reactions typically occur with high (95-99\%) stereospecificity. These reactions are therefore of potential use in drug synthesis, where the need for chiral products in certain reaction steps is high. These vegetable-based, enzymatic reactions can be repeated many times over (6-7 times) without loss of system reactivity, and have minimum energy requirements (room temperature for 3 days). As indicated, ${ }^{56}$ this area of chemistry has a very high potential for future development in less-developed countries around the world where the range of potential reagents (such as vegetables or other commercial plants) is high, and where facilities for product determination may be limited. Long term, incorporation of these reactions into synthetic sequences for drug manufacture may make the delivery of cheaper, semisynthetic products through local production a viable alternative to costly importation.

\section{Information systems}

It was pointed out earlier that for thousands of years humankind has been collecting and documenting information on the use of plants as specific medicinal agents. Though extremely important in themselves, unfortunately these compilations are highly scattered and, by their nature, non-interactive. With the advent of database systems, the possibility exists to extend this collection of knowledge for a global health benefit. Unfortunately, there is no single place in the world where the information on the ethnomedical use of plants is being collected, collated, analyzed, and used as a resource for developing strategies for medicinal plant development. ${ }^{5,9,10,62}$ This, it must be made clear, is a global health care tragedy of very significant proportions. Collecting information in many different forms about the usage, the effectiveness, and the distribution of medicinal plants is an important first step in justifying the conservation and sustainable development of common, threatened, and endangered medicinal plants, and in prioritizing steps to protect critical endangered medicinal plant resources. At the same time, there is the established need to balance the quest for information with indigenous rights of ownership to such knowledge and the responsibilities therein. 5, 9,10,62

Perhaps the leading country in the world in assessing the contemporary status of their plant and animal resources is India, which recently published the Jeeva sampada (wealth of bioresources). ${ }^{63}$ This database collection of information regarding the economically important and medicinal plants, the animal and microbial resources, and the marine resources, involved the sustained efforts of about 400 scientists from 150 organizations. The database comprises 8,200,000 records for over 39,000 species, and is probably the largest bioresources database in the world. Hopefully, this effort will serve as both a model and an inspiration to other countries to compile their own information systems on country-wide biodiversity. The challenge 
then will be to accumulate this information for global analysis so that optimum use can be made of the available resources and the threatened and endangered species identified.

\section{Good agricultural and collection practices}

It is clearly not an advisable long-term practice to collect medicinal plants indiscriminately; alternative pathways for medicinal plant availability must be clearly delineated. In 2003, WHO published the "WHO Guidelines for Good Agricultural and Collection Practices (GACP) for Medicinal Plants" a 78-page guide aimed at contributing to aspects of quality assurance, guiding the formulation of national and/or regional GACP guidelines, and encouraging and supporting the sustainable cultivation and collection of medicinal plants. ${ }^{64,65}$ Last year (2007), a new standard for the collection of medicinal plants was launched at the World Organic Trade Fair. ${ }^{66}$ The International Standard for Sustainable Wild Collection of Medicinal and Aromatic Plants (ISSC-MAP) was developed by a number of German government agencies, industry associations, non-governmental agencies, companies, and the wildlife trade monitoring network TRAFFIC. The standard is based on six principles, including maintaining plant resources, legal compliance with respect to access, responsible management and business practices, and preventing negative environmental impacts. The Medicinal Plant Specialist Group within the IUCN Species Survival Commission ${ }^{67}$ publishes an important newsletter, Medicinal Plant Conservation which discusses a diversity of issues, and presents the results of studies on strategies to conserve and sustainably use medicinal plant species. As mentioned earlier, it is well-recognized that the transition to cultivation from wild-crafting is not a straightforward one. ${ }^{19}$

Besides cultivation as a crop, are there other approaches which can preserve important medicinal plant resources? One possibility is to look for alternative sources of the active constitutent(s) within the same plant material (plant part substitution), within the same plant genus, or, if the active principle is known, for plants with the same or similar constituents. Van Staden and co-workers in South Africa have examined this possibility with four local plants where the bark or an underground part is used and the plant destroyed. ${ }^{68}$ The same group has also looked at the possibility of using the aerial parts of several Cryptocarya species, rather than the bark of the rare Ocotea bullata, both in the Lauraceae, as cyclooxygenase inhibitors. ${ }^{69}$ There is a clear need to develop research programs in this area where the root, rhizome, or bark is the medicinal plant part to assess whether there are renewable plant parts (e.g. leaves or fruits), or alternative plant sources which could serve as potential replacements. One very serious issue which has to be addressed scientifically is safety. While a replacement plant or plant part may be effective, it may also possess other constituents which offer a very different level of toxicity which has to be explored for safety and efficacy in each instance before a substitution could become a rational and realistic replacement. It cannot be assumed that all parts of a medicinal plant are necessarily "safe", even if one part, based on long-standing use, appears to be safe.

Another facet of sustainability which remains to be explored is the value of each individual plant in a multicomponent preparation. For example, if a particular formula is comprised of eight plant materials, the question is whether all of these are necessary to obtain the complete effect of the preparation. Perhaps only three or four of the medicinal plants are actually necessary for effectiveness, in which case, the harvesting of four other plants for that particular remedy can be reduced. Similar considerations also apply to establishing the optimum time for harvesting, to dosing studies relating to biological activity, and optimizing dosing regimens for a more sustainable product.
The ability to store medicinal plants, or their extracts, for extended periods post-harvest, and be assured that effectiveness is retained, is another critical aspect of sustainable plant development. If successful, it could mean that there would be less wastage of plant material. However, there is very little information currently available on how long plant materials and their biologically active constituents remain effective under standardized storage conditions of heat, light and humidity. A medicinal plant may or may not retain activity if it is stored for an extended period. Shibata has demonstrated that several key medicinal plants (licorice, ginseng, and rhubarb), stored for over 1200 years in carefully controlled conditions in the Imperial Treasure House, Shosoin, in Nara since 756 A.D., were essentially identical in constituents to those harvested today. ${ }^{70}$ However, a study of nine medicinal plants in South Africa showed that even 90 day-old material began to show serious losses of cyclooxygenase activity, ${ }^{71}$ although antibacterial activity was retained for longer periods. Bonjar showed that the antimicrobial activity of the extracts of 45 medicinal plants against 10 microorganisms was unchanged after 18 months of storage at room temperature. ${ }^{72}$ For the development of quality control processes for medicinal plants, stability studies on individual plant preparations, both prior to, and after reaching, the point of sale, are extremely important from a public health care perspective.

\section{Other technologies impacting medicinal plant sustainability}

It is also essential to examine what other technologies can be brought to bear and integrated into the determination and cultivation of medicinal plants for global health care. Two aspects will be very briefly touched on: i) biotechnology, and ii) location and detection techniques. Finally, it is important that all of the available technological innovations are incorporated into the drive to sustainable medicinal plant development in the future. As such, there is a need to drastically change the strategies deployed for medicinal plant detection in the field.

\section{Biotechnology}

There are many different aspects of the application of biotechnology to the development and sustainability of medicinal plants. Tripathi and Tripathi ${ }^{73}$ have discussed the importance of biotechnology on the development of medicinal plants. The propagation of seedlings of threatened or endangered medicinal plants, or the control of seedling conditions to enhance field planting, is now of substantial investigation. In India, the Department of Biotechnology has established three national gene banks for the conservation of medicinal and aromatic plants, ${ }^{32}$ as well as initiating numerous projects on the ex situ micropropagation of local species of medicinal importance (e.g. Swertia chiratia, Crataeva magna, Gymneme sylvestre, Garcinia indica, Premna corymbosa, and Oroxylum indicum, etc.), and the propagation of plant species to produce important established therapeutic agents such as paclitaxel and camptothecin. In Brazil, the need for acquisition and selection programs for the maintenance of supplies of Pilocarpus jaborandi became urgent. ${ }^{74}$

\section{Location and detection techniques}

The location of medicinal plants in the wild is obviously a critical aspect relating to the issue of wild-crafting, and one aspect of the long-term solution to the sustainability of needed resources. Monitoring population trends of medicinal plants over time will evolve as an activity of increasing significance. From a conservation perspective, it is also important, as mentioned above, to harvest both wild and cultivated medicinal plants at the time which optimizes safety and effectiveness. In this way, plant usage is maximized and sustainability enhanced. In the past, local persons experienced in plant collection "knew", through traditional practice, when to collect a particular me- 
dicinal plant. For reasons of safety, efficacy, and public health, there is a need now to place such decision-making on a scientific basis.

It is important to incorporate geographical information systems (GIS) for the mapping of plant resources. A number of herbarium and botanic garden websites now include information from the original accession site in maps which can indicate where those collections were made. Obviously, the quality and utility of this information relates directly to the accuracy of the notation on the herbarium specimen. What is needed as a next step is a unification of this information from all of the major herbaria of the world, so that from a single website it would be possible to determine the collection location of every plant ever collected. This would be an intensely valuable asset for plant conservation in general, and for medicinal plant conservation in particular. Plotting the resources of medicinal plant use for global health care and making that information available on-line and accessible will be a critical need in the future. However, these are past data, and do not reflect changes in distribution or access which may have occurred since specimens were collected. Contemporary, in-field based information is therefore critical in addressing local needs, now and for the future. Few studies have been reported on the use of GIS for medicinal plant detection and conservation. ${ }^{75}$

The Foundation for Revitalization of Local Health Traditions (FRLHT) is one of the groups in India which has pioneered aspects of medicinal plant conservation. It is supported by the Ministry of Environment and Forests, and has developed 54 medicinal plant conservation areas in southern India and an Environmental Information System, which offers a database, and discusses the conservation of 930 species of medicinal plants traded throughout India. ${ }^{76}$ This website also has GIS maps of the distribution in India and neighboring countries of the 930 species traded and of 7637 additional medicinal plant species. Other efforts in India, ${ }^{77,78}$ in the Sinai desert in Egypt, ${ }^{79}$ and Canada ${ }^{80,81}$ are also using GIS data to map the distribution of medicinal plants for conservation purposes. Semwal and Sardhi have used GIS mapping in an evaluation of 350 plant species in the Kadarnath Wildlife Sanctuary, ${ }^{82}$ and Menon and Bawa have applied GIS in a landscape ecology and spatial analysis approach to establish deforestation and forest fragmentation rates and consequent changes in biodiversity. ${ }^{83}$ GIS has also been used to develop probabilities for the location of medicinal plants followed up with ground tracking, ${ }^{84}$ and to identify possible locations of rare native plants. ${ }^{85}$

Russell-Smith and colleagues in Sri Lanka ${ }^{86}$ have conducted an inventory of the medicinal plants of five medicinal plant conservation areas in that country. The techniques involved i) assessments of distributions and ecological requirements at 898 inventory plots, and ii) topographic mapping augmented by Landsat ${ }^{\mathrm{TM}}$ imagery. Over 140 medicinal plant species were sampled, and the potential for sustainable harvest was assessed for 34 priority medicinal plant species. In Ghana, a project funded by the Darwin Initiative for the Survival of the Species is a collaborative effort on the conservation and sustainable use of medicinal plants. ${ }^{87}$ Besides the medicinal plant garden development, a critical component is the information management and GIS analyses of medicinal plant species.

The application of lasers for remote sensing of compounds and plants goes back well over 30 years, ${ }^{88}$ particularly Raman spectroscopy, ${ }^{89}$ near infrared FT-IR spectroscopy, ${ }^{90}$ and attenuated total reflection FT-IR (ATR/FT-IR) spectroscopy ${ }^{91}$ have been used. Various spectral techniques have been used in agriculture and viticulture for determining when crops are ready for harvesting, etc.. ${ }^{75,92}$ Wine crops and their distribution can be quite accurately monitored by remote sensing for the appropriate time to harvest the grapes.

Hyperspectral imaging of medicinal plants is in its infancy. ${ }^{93}$ Surface enhanced Raman spectroscopy (SERS) analysis of plants has been conducted with silver-coated glass fiber tips ${ }^{94}$ and a micro-Raman spectroscopy technique has been used for the investigation of alkaloids present in crude plant materials. ${ }^{95}$ The alkaloids in opium capsules have been studied with ATR/FT-IR and FT-Raman-spectroscopy. ${ }^{96}$ A fiber optic Raman probe and portable Raman spectrograph have been used for cocaine identification ${ }^{97}$ and near-IR Raman has been used for cocaine identification in mixtures. ${ }^{98}$ Recently, femtosecond adaptive spectroscopic technique via coherent anti-Stokes Raman spectroscopy (FAST-CARS) has been used for bacterial system identification. ${ }^{99}$ The remote sensing of medicinal plants, in addition to drug plants, will be of vital significance in the future for gauging the illicit collection of plants and the optimum collection time for medicinal plant harvesting once active (or at least marker) compounds have been identified.

\section{Pharmacognosy in a suitcase}

Pharmacognosy is the "study of biologically active natural products"; ${ }^{100}$ it involves plant, marine, microbial and mammalian taxonomy, chemistry, and biology. Over the years, strategies in pharmacognosy, particularly for drug discovery and for traditional medicine validation and standardization, have focused on bringing samples, often dried plant samples, in large numbers, from the field to the laboratory for evaluation.

In previous discussions of the future of natural products in health care, ${ }^{5,8-12}$ it has been indicated that a paradigm shift is needed for medicinal plant research, including traditional medicine quality control and drug discovery. This shift has its basis the ecological and environmental need to do as much of the botanical, chemical, and biological science in the field on the local plant materials. Thus, rather than bringing the dried plant material back to the laboratory, frequently with high transportation costs, and conducting the respective scientific evaluations there, the respective technologies are brought to the field. This strategy of incorporating multiple and diverse technologies into a field-based, portable laboratory of instruments, based on the integration of the most advanced electronic and nano-technologies, has been termed "Pharmacognosy in a Suitcase". ${ }^{12}$

What are the critical issues we would like to address in the field acquisition of medicinal plants? They include: i) where are we collecting? ii) what is the identity of the plant? iii) if they are known, does the plant have the chemicals of interest? iv) does the plant material have the anticipated or activity, or what activities might it possess? and v) how does this newly gathered knowledge, in whole or in part, relate to prior knowledge of the species? In order to be able to address these questions in the field, what would be some of the technologies that we would wish for?

\section{A mini-PCR machine}

There are already nano-technology-based, battery-operated, miniPCR machines available ${ }^{101}$ which could provide a DNA profile of a plant material within an hour. This information could be compared on-site, or through satellite communications with large databases currently being established. One can imagine within a few years that will allow the remote, unambiguous identification of plant materials.

\section{Micro-extraction and separation}

Nano systems for micro-extraction of materials using solvents located in a multivalve matrix, followed by moderate pressure chromatography to effect a preliminary clean-up, will rapidly afford microliter samples suitable for analysis.

\section{Microarray evaluation}

A microarray system involving either whole or partial human genome screens which are capable of determining the genetic basis of the effectiveness of medicinal plants will be an essential tool for field work. It will require that there be large databases available of the 
genetic modulations induced by a large number of diversely acting medicinal plants. This will permit in-field data to be compared in ter$\mathrm{ms}$ of the plant of interest, or a new plant to determine close relatives as a potential substitute from a biological perspective. Again, this is an area of medicinal plant research that is in its early stages. ${ }^{102}$

\section{A mini-mass spectrometer}

Mini-mass spectrometers employing a rectilinear ion trap technology that occupy a very small volume and weigh only a few pounds are now available for monitoring of low molecular weight metabolites (to a mass of about $\mathrm{m} / \mathrm{z}, 500$ ) in complex matrices. ${ }^{103}$ Smaller and more sophisticated systems are under continuous development

\section{Location and remote sensing}

The instrument package would incorporate both normal and infra-red cameras, and a satellite-linked, global positioning system for accurate location determination and tracking of individual species from previous collection expeditions and global herbarium data. Depending on the purpose, remote sensing through various forms of integrated hyperspectral imaging of specific compounds in crude plant materials would be incorporated.

\section{Communications, data-base access and solar power}

Global access to large databases through appropriate satellite communications networking will be essential for the efficient appreciation of the data obtained in the field in real time. Among the databases to be accessed will be those which i) contain DNA data on plants, ii) have the location and occurrence of specific plants based on the acquisition of global positioning information from existing herbarium samples, iii) can provide summaries of the chemical constituents known for specific plants, iv) can summarize the known in vitro, in vivo biological, and the clinical data of specific plants and their constituents, and v) can compare traditional uses of specific plants on a global basis. Solarpowered instruments or battery packs that can be incorporated into everyday wear will be essential to maintain the power needs for the various instruments and computers that will be required.

"Pharmacognosy in a Suitcase" is an important concept to enhance medicinal plant research in the field, and at the same time determine the importance of numerous plants as potential medicinal agents. It would aid conservation and sustainability efforts for medicinal plants and provide important information to enhance local health care practices involving medicinal plants.

\section{CONCLUSIONS}

There is a synergy in the Earth such that only when both human health and eco-health improve will a more sustainable system for humankind evolve. As the Earth strains to support the health care of a burgeoning population, a number of important steps are required to ascertain and assure that there are adequate supplies of critical synthetic drugs and medicinal plants available for the future. This brief paper has outlined the need to consider synthetic and natural drugs as requiring a sustainable base for the future health care and the care of the Earth. Several aspects of these efforts are discussed, including the use of vegetables as potential reagents for drug synthesis, the assessment and monitoring of the degree of threat to needed medicinal plants, and the use of advanced technologies and nanotechnology to find and track medicinal plant populations and most importantly to unambiguously identify them and validate their bioactivity in the field. Only through the integration of these ideas and other high technology strategies will the global needs for medicinal agents be assured for the maintenance and advancement of public health in the future.

\section{REFERENCES}

1. http://www.un.org/apps/news/story.asp?NewsID $=24704 \& \mathrm{Cr}=\mathrm{Climate} \&$ Cr1, accessed in April 2008.

2. http://www.commondreams.org/headlines06/1227-02.htm, accessed in April 2008

3. Anonymous; 2005, http://www.millenniumassessment.org/en/Synthesis. aspx, accessed in April 2008

4. McCarthy, M.; The Independent 2006, October 4

5. Cordell, G. A.; Phytochem. Revs. 2002, 1, 261.

6. Cordell, G. A.; Rev. Quim. 2002, 16, 5.

7. Cordell, G. A.; Rev. Quim. 2003, 17, 1.

8. Cordell, G. A.; Rev. Quim. 2004, 19, 33.

9. Cordell, G. A.; Colvard, M. D.; J. Ethnopharmacol. 2005, 100, 5, and references therein.

10. Cordell, G. A. In Proceedings of the Second Women's Health and Asian Traditional Medicine Conference and Exhibition; Rao, A. N., ed.; Kuala Lumpur, 2006, p. 93.

11. Cordell, G. A.; Colvard, M. D.; Arkivoc, vii, 2007, 97.

12. Cordell, G. A.; Michel, J. In Proceedings of the Third Women's Health and Asian Traditional Medicine Conference and Exhibition; Rao, A. N., ed.; Kuala Lumpur, 2007, p. 15.

13. Clark, G.; A Farewell to Alms: A Brief Economic History of the World, Princeton Press: Princeton, 2007, p. 440.

14. Anonymous; 2007, www.infoplease.com/ipa/A09354556.html, accessed in April 2008

15. http://www.stateline.org/live/details/story?contentId=235948, accessed in April 2008.

16. Anonymous; National Policy on Traditional Medicine and Regulation of Herbal Medicines - A Report of a WHO Global Survey, WHO: Geneva, 2005 , p. 168.

17. Bannerman, R. H.; World Health Forum 1982, 3,8 .

18. Farnsworth, N. R.; Akerele, O.; Bingel, A. S.; Soejarto, D. D.; Guo, Z.; Bull WHO 1985, 63, 965

19. Schippmann, U.; Leaman, D. J.; Cunningham, A. B.; FAO Report, Rome, 2002, p. 21.

20. Anonymous; 2007, www.aspirin-foundation.com, accessed in April 2008.

21. Drummond, A.; Kwok, S.; Morgan, J.; Durrington, P. N.; Quart. J. Med. 2002, 95, 23.

22. Heuser, S.; Boston Globe, 2007, http://www.boston.com/business/specials/bio2007/articles/high_costs/, accessed in April 2008.

23. Boutayeb, A.; Int. J. Equity Hlth. 2007, 6, 20.

24. http://www.accessmed-msf.org/main/medical-innovation/introductionto-medical-innovation/what-is-wrong-with-r-d-today/, accessed in April 2008.

25. Anonymous; 2007, www.cites.org/eng/disc/what.shtml, accessed in April 2008.

26. Spicuzza, M.; 1999, www.metroactive.com/papers/cruz/03.03.99/ herbs1-9909.html, accessed in April 2008.

27. http://www.nps.gov/shen/naturescience/upload/SHEN_NR_Plant_Protection_2005-03.pdf, accessed in April 2008.

28. de Selincourt, K.; New Sci. 1992, 1882, 7.

29. Akerele, O.; Heywod, V.; Synge, H., eds.; The Conservation of Medicinal Plants, Cambridge University Press: Cambridge, 1991, p. 382.

30. Chaudhuri, A. B.; Endangered Medicinal Plants, Eastern Book Co.: Delhi, 2007, p. 311.

31. Anonymous; 2007, www.dbtindia.nic.in/r\&d/med\&aroplants.html, accessed in April 2008.

32. Tandon, V.; Med. Plant Conserv. Newslett. 1996, 2, 12.

33. Gupta, A.; Vats, S. K.; Lal, B.; Curr. Sci. 1998, 75, 565.

34. Ved, D. K.; Anjna, M.; Shankar, D.; Curr. Sci. 1998, 75, 341

35. Hamilton, A. C.; Biodivers. Conserv. 2004, 13, 1477. 
36. Anonymous; Conservation assessment and management prioritization for the medicinal plants of Jammu-Kashmir, Himachal Pradesh and Uttaranchal. Foundation for Revitalization of Local Health Traditions: Bangalore, India, 2003.

37. Kala, C. K.; Dhyani, P. P.; Sajwan, B. S.; J. Ethnobiol. Ethnomed. 2006, 2,32 .

38. Kala, C. P.; Biol. Conserv. 2000, 93, 371.

39. Anonymous; Report of the Task Force on Conservation and Sustainable use of Medicinal Plants, Government of India Planning Commission,:New Delhi, 2000, p. 179.

40. Anonymous; 2003, http://forest.ap.nic.in/Medicinal\%20Plant.htm, accessed in April 2008.

41. Government of Sikkim; Lampokhri Medicinal Plants Conservation Zone, Notification no.: 890/FEWMD, 2006.

42. Pushpangadan, P.; Thomas, J.; www.bgci.org/congress/congress_1998_ cape/html, accessed in April 2008.

43. Olsen, C. S.; Biol. Conserv. 2005, 125, 505.

44. Kala, C. P.; Conserv. Biol. 2005, 19, 368.

45. Rukangira, E.; 2001, www.conserveafrica.org.uk/herbal_industry.html, accessed in April 2008.

46. Inggs, M.; 2007, http://www.busrep.co.za/index.php?fSectionId=\&fArt icleId=4023222, accessed in April 2008.

47. Anonymous; 2007, www.conserveafrica.org.uk/natural_products.html, accessed in April 2008.

48. Anonymous; People's Daily October 28, 2000.

49. SEPA; National status report on biodiversity of China, State Environment Protection Agency, China Environment Press: Beijing, 1997.

50. Huang, J.; Pei, S.; Long, C.; Econ. Bot. 2004, 58, S253.

51. Pei, S.; Huai, H.; Yang, L.; 2004, http://www.plantlife.org.uk/international/assets/important-plant-areas/Other\%20IPA\%20projects\%20 around\%20the\%20world/PDF-ChinaIPA.pdf, accessed in April 2008.

52. Vieira, R. F. In Perspectives on New Crops and New Uses; Janick, J., ed.; ASHA Press: Alexandria, 1999, p. 152.

53. Reisch, M. S.; Chem. Eng. News 2001, September 3, 17.

54. Rouhi, A. M.; Chem. Eng. News 2002, April 22, 30.

55. Anastas, P. T.; Warner, J. C.; Green Chemistry: Theory and Practice, Oxford University Press: New York, 1998, p. 30.

56. Cordell, G. A.; Lemos, T. L. G.; Monte, F. J. Q.; de Mattos, M. C.; J. Nat. Prod. 2007, 70, 478.

57. Horváth, I. T.; Anastas, P. T.; Chem. Revs. 2007, 107, 2169.

58. Horváth, I. T.; Anastas, P. T.; Chem. Revs. 2007, 107, 2167.

59. http://www.blacksmithinstitute.org/ten.php, accessed in April 2008.

60. Eaton, L.; BMJ 2003, 327, 642 .

61. Bommarius, A. S.; Riebel, B. R.; Biocatalysis, Wiley-VCH: Weinheim, 2004, p. 611.

62. Cordell, G. A.; Phytochemistry 2000, 55, 463.

63. Natesh, S.; Curr. Sci. 2006, 91, 860.

64. Anonymous; WHO Guidelines for Good Agricultural and Collection Practices (GACP) for Medicinal Plants, WHO: Geneva, 2003, p. 78.

65. Anonymous; 2007, www.unobserver.co/printen.php?id=1428.html, accessed in April 2008.

66. Anonymous; 2007, www.icstd.org/biores/07-03-02/story3.htm, accessed in April 2008.

67. Anonymous; 2007, www.iucn.org/themes/ssc/sgs/mpsg/main, accessed in April 2008

68. Zschocke, S.; Rabe, T.; Taylor, J. L.; Jaeger, A. K.; van Staden, J.; J. Ethnopharmacol. 2000, 71, 281.

69. Zschocke, S.; van Staden, J.; J. Ethnopharmacol. 2000, 71, 473.

70. Shibata, S.; Int. J. Pharmacogn. 2003, 32, 75.

71. Stafford, G. I.; Jaeger, A. K.; van Staden, J.; J. Ethnopharmacol. 2005, 97, 107.

72. Bonjar, S.; J. Ethnopharmacol. 2004, 94, 301.
73. Tripathi, L.; Tripathi, J. N.; Trop. J. Pharm. Res. 2003, 2, 243.

74. Pinheiro, C. U. B.; Econ. Bot. 1997, 51, 49.

75. Campbell, J. B.; Introduction to Remote Sensing, Guilford Publications: New York, 2007, p. 626.

76. Anonymous; 2007, http://envis.frlht.org.in, accessed in April 2008.

77. Anonymous; 2007, http://dbtindia.nic.in/r\&d/bioprosmoltax.html, accessed in April 2008

78. Varaprasad, K. S.; Sivaraj, N.; Ismail, M.; Pareek, S. K. In Advances in Medicinal Plants; Reddy, K. J.; Bahadur, B.; Bhadraiah, B.; Rao, M. L. N., eds.; Universities Press: New Delhi, 2007, p. 320.

79. Anonymous; 2007, www.millenniumassessment.org/en/SGA.Egypt. aspx, accessed in April 2008.

80. Ames, D.; 2002, www.nativeorchid.org/dorisSE01report.htm, accessed in April 2008.

81. Anonymous; 2007, www.iucn.org/places/canada/prog/index.htm, accessed in April 2008.

82. Semwal, D. P.; Saradhi, P. P.; 2006, www.gisdevelopment.net/proceedings/mapindia/2006/poster/mi06pos_174abs.htm, accessed in April 2008

83. Menon, S.; Bawa, K. S.; Curr. Sci. 1997, 73, 134.

84. Mustalish, R. W.; Evans, B.; Tucker, C.; Klein, K.; Craker, L. E.; Nolan, L.; Shetty, K.; Acta Horticult. 1996, 426, 123.

85. Sperduto, M. B.; Congalton, R. G.; Photogramm. Eng. Rem. Sens. 1996, 62,1269

86. Russell-Smith, J.; Karuratne, N. S.; Mahindapala, R.; Biol. Conserv. 2006, 132, 22.

87. Abbiw, D.; Agbovie, T.; Akutteh, B.; Amponsah, K.; Dennis, F.; Ekpe, P.; Gillett, H.; Ofosuhene-Djan, W.; Owusu-Afriyie, G.; 2002, http:// www.unep-wcmc.org/species/plants/ghana/, accessed in April 2008.

88. Collis, R. T. H.; Russell, P. B.; Ecol. Stud. 1976, 18, 110.

89. Petry, R.; Schmitt, M.; Popp, J.; Chem. Phys. Chem. 2003, 4, 14.

90. Himmelsbach, D.; Akin, D. E.; J. Agric. Food Chem. 1998, 46, 991.

91. Schulz, H.; IIIrd World Congress on Medicinal and Aromatic Plants, 2005, vol. 5; http://www.actahort.org/books/679/679_22.htm, accessed in April 2008.

92. Johnston, C. A.; Methods in Ecology Series, Blackwell Science: Malden, 1998, p. 239.

93. Campbell, J. B.; Introduction to Remote Sensing, $4^{\text {th }}$ ed., The Guilford Press: New York, 2007, p. 625.

94. Gessner, R.; Rösch, P.; Keifer, W.; Popp, J.; Biopolymers (Biospectrosсору) 2002, 67, 327.

95. Urlaub, E.; Popp, J.; Kiefer, W.; Bringmann, G.; Koppler, D.; Schneider, H.; Zimmerman, U.; Schrader, B.; Biospectroscopy 1998, 4, 113.

96. Schulz, H.; Baranska, M.; Quilitzsch, R.; Schütze, W.; Analyst 2004, 129, 917.

97. Carter, J. C.; Brewer, W. E.; Angel, S. M.; Appl. Spectrosc. 2000, 54, 1876.

98. Ryder, A. G.; O’Connor, G. M.; Glynn, T. J.; J. Raman Spectrosc. 2000, $31,221$.

99. Pestov, D.; Murawski, R. K.; Ariunbold, G. O.; Wang, X.; Zhi, M.; Sokolov, A. V.; Sautenkov, V. A.; Rostovstev, Y. V.; Dogariu, A.; Huang, Y.; Scully, M. O.; Science 2007, 316, 265.

100. Cordell, G. A. In Studies in Natural Products Chemistry, vol. 13, Bioactive Natural Products (Part A); Atta-ur-Rahman; Basha, F. Z., eds.; Elsevier Science Publishers: Amsterdam, 1993, p. 629.

101. Agrawal, N.; Hassan, Y. A.; Ugaz, V. M.; Angew. Chem., Int. Ed. 2007, 46,4316

102. Roy, S.; Khanna, S.; Hiral, R.; Rink, C.; Phillips, C.; Preuss, H.; Subbaraju, G. V.; Golakoti, G.; Krishnaraju, A. V.; Bagchi, M.; Bagchi, D.; Sen, C. K.; DNA Cell Biol. 2005, 24, 244.

103. Gao, L.; Song, Q.; Patterson, G. E.; Cooks, R. G.; Ouyang, Z.; Anal. Chem. 2006, 78, 5994. 